\title{
Díaz Lacayo, Aldo. (2015) La Guerra Nacional: Omisiones históricas. Managua: Aldilá
}

Luis Javier Gaitán Lugo

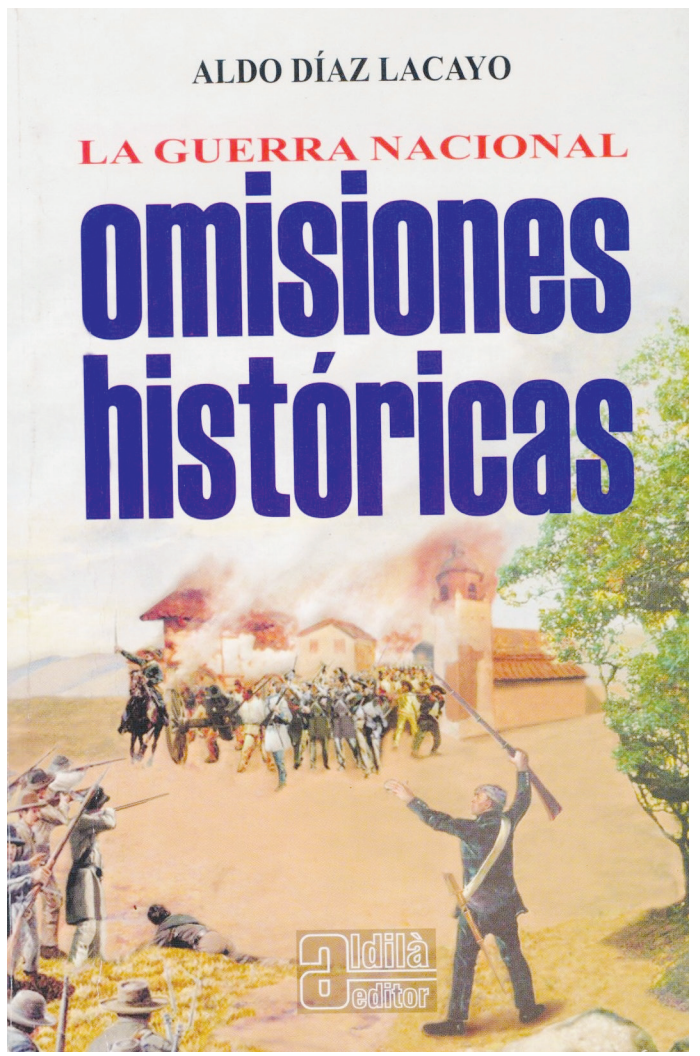

Para la ciencia histórica no hay ningún tema agotado a los nuevos análisis e interpretaciones de los procesos sociales por los cuales transitamos los seres humanos. Esto tiene mayor importancia, cuando por tradición dentro de los programas de historia se enseñan una serie de verdades a medias o equivocadas socializadas a todos los niveles educativos.

Surge entonces las siguientes interrogantes ¿Para qué otro libro que hable de la Guerra Nacional? ¿Qué nuevo aporta? ¿Cuál va ser el beneficio científico para la sociedad nicaragüense?
La respuesta, partiendo del libro del autor Aldo Díaz Lacayo, es develar los vacíos académicos presentes en los textos educativos a todos los niveles.

Es bueno mencionar las obras y autores que preceden la de Díaz Lacayo con el fin de ubicarla como aporte al tema:

1. Memorias para la historia de la Campaña Nacional contra el filibustero de 1856 y 1857 de Jerónimo Pérez luego compilados en sus Obras Históricas Completas.

2. Cuarenta años de historia de Nicaragua de Francisco Ortega Arancibia

3. Historia de Nicaragua de José Dolores Gámez.

4. La Guerra Nacional de Ildefonso Palma Martínez.

5. La Guerra Nacional de Centroamérica de Marco Aurelio Soto Valenzuela.

De igual manera comentar algunos planteamientos usados por académicos y estudiantes, los cuales son tenidos como verdades absolutas:

1. Al acercarse las conmemoraciones de las fiestas patrias, vemos la gran cantidad de estudiantes que visitan la Hacienda San Jacintoy son entrevistados por periodistas quienes les hacen preguntas como: ¿A qué se debe su visita? ¿Qué representa este lugar? ¿Qué se conmemora el 14 de septiembre? las respuestas poco acertadas de los jóvenes y el morbo de los periodistas por evidenciar las carencias de los entrevistados, dan la sensación de vacíos en temas relacionados con la historia, de manera particular, entre los jóvenes. 
2. Otro comentario. Se maneja en la enseñanza primaria y secundaria que la Guerra Nacional es un suceso meramente nicaragüense. De ahí que los únicos héroes que estudiamos sean: Andrés Castro, José Dolores Estrada, Enmanuel Mongalo y nada más, cercenando la amplitud del proceso y la variedad de personajes que fueron partícipes de la misma.

Como se ha sugerido, de los anteriores vacíos $\mathrm{u}$ omisiones es que trata el libro del Doctor Díaz Lacayo. Para tener una idea general de los aspectos relevantes que sustenta el trabajo, es adecuado enumerarlos de manera sucinta:

La aclaración del uso del término Nacional, que en el contexto hace alusión a la patria grande, a la nación centroamericana, y que por ende la Guerra Nacional tiene por primera y última causa la defensa de la soberanía centroamericana y no nicaragüense.

Explica cómo la contratación de mercenarios puedo haber sido utilizada por uno $\mathrm{u}$ otro bando político, en este sentido, por los democráticos (leoneses) también pudo haberlo sido por los legitimistas (conservadores). Es más, cuando Walker se toma Granada, miembros de este último bando se adhieren al proyecto del filibustero.

Hasta el día de hoy solemos mencionar la actitud de poca identidad patriótica de Patricio Rivas, Ponciano Corral y hasta de Máximo Jerez al ser parte en un principio del gobierno de William Walker. Pero olvidamos la ruptura de cada uno de ellos con el filibustero, y por tanto deben ser reivindicados.

se desconocía la participación del clero en la guerra nacional. Los presidentes de los Estados Centroamericanos hicieron invocaciones al Altísimo para motivar la participación de sus pobladores en el conflicto. De igual manera, los obispos de los Estados también emitieron proclamas dado que estaban siendo afectados en sus dominios religiosos, con la posibilidad del ingreso del protestantismo en el territorio. Todos emitieron proclamas excepto el obispo nicaragüense, entonces era cercano a Walker.

Definir cuál es el verdadero sentido de la batalla de San Jacinto. En el imaginario popular se sostiene que fue la batalla decisiva, la más importante y la única que se resalta, De hecho hubo otras batallas más cruentas y de mayor interés estratégico, entonces ¿por qué se le resalta tanto? En principio fue una batalla donde solo participaron fuerzas nicaragüenses. La derrota de los filibusteros y la muerte de Byron Cole moralizaron a las fuerzas aliadas y fuerzas de Nicaragua. Se rescata la presencia de los indígenas flecheros, mencionado por Jerónimo Pérez.

el autor hace énfasis en el estudio de la Guerra Nacional de manera amplia. Considera el autor que debe de verse como una manifestación de las pugnas geopolíticas entre Estados Unidos y España, Estados Unidos e Inglaterra y Estados Unidos y Francia, casos todos documentados en la obra.

Es notable la labor erudita que presenta la obra y la profundidad del análisis con que se estudian cada uno de los procesos planteados, brindando nuevas luces a la Guerra Nacional en la búsqueda de una historia crítica. De igual forma, debe fomentarse el estudio de estos temas y dotar a los estudiantes de un conocimiento amplio, abarcador y no excluyente. 